\begin{tabular}{|c|c|c|}
\hline \multirow{3}{*}{$\begin{array}{r}\text { Case Reports in } \\
\text { Gastroenterology }\end{array}$} & \multicolumn{2}{|c|}{ Case Rep Gastroenterol 2013;7:37-43 } \\
\hline & $\begin{array}{l}\text { DOI: } 10.1159 / 000346925 \\
\text { Published online: January 23, } 2013\end{array}$ & $\begin{array}{l}\text { (c) } 2013 \text { S. Karger AG, Basel } \\
1662-0631 / 13 / 0071-0037 \$ 38.00 / 0 \\
\text { www.karger.com/crg }\end{array}$ \\
\hline & $\begin{array}{l}\text { This is an Open Access article licensec } \\
\text { NonCommercial-NoDerivs } 3.0 \text { Lice } \\
\text { online version of the article only. Di }\end{array}$ & $\begin{array}{l}\text { Is of the Creative Commons Attributio } \\
\text { er.com/OA-license), applicable to th } \\
\text { on-commercial purposes only. }\end{array}$ \\
\hline
\end{tabular}

\title{
Simultaneous Resection of Disseminated Hepatocellular Carcinoma and Colon Cancer
}

\author{
Yuki Haga $^{a}$ Tetsuhiro Chiba ${ }^{a}$ Gaku Ohira $^{b}$ Fumihiko Kanai ${ }^{a}$ \\ Hajime Yokota ${ }^{c}$ Tenyu Motoyama ${ }^{a}$ Sadahisa Ogasawara ${ }^{a}$ \\ Eiichiro Suzuki $^{\mathrm{a}}$ Yoshihiko Ooka $^{\mathrm{a}}$ Akinobu Tawada ${ }^{\mathrm{a}}$ Hideaki Miyauchi ${ }^{\mathrm{b}}$ \\ Hisahiro Matubara ${ }^{b}$ Osamu Yokosuka ${ }^{a}$ \\ Departments of ${ }^{a}$ Gastroenterology and Nephrology, ${ }^{b}$ Frontier Surgery and ${ }^{c}$ Radiology, \\ Graduate School of Medicine, Chiba University, Chiba, Japan
}

\section{Key Words}

Hepatocellular carcinoma - Radiofrequency ablation · Peritoneal metastasis · Tumor seeding

\begin{abstract}
A 75-year-old woman with abdominal pain and vomiting was admitted to our hospital. Colonoscopy showed an advanced colon cancer that encompassed the entire circumference of the descending colon's lumen. The patient was diagnosed with occlusive ileus associated with the colon cancer. She had been watched for liver cirrhosis due to the hepatitis $C$ virus and received radiofrequency ablation therapy for hepatocellular carcinoma (HCC) 6 years previously. Although she exhibited a gradual increase in serum levels of $\alpha$-fetoprotein and PIVKA-II starting 2 years before admission, no tumors were detected in the liver by abdominal ultrasonography and computed tomography. On admission, contrast-enhanced computed tomography revealed not only the colon cancer but also a tumor adjacent to the cecum. Both tumors were successfully removed by surgery and a pathological analysis revealed that the cecum tumor was poorly-differentiated HCC. The serum levels of $\alpha$-fetoprotein and PIVKA-II declined markedly after the operation and no masses considered as peritoneal metastasis have been detected to date. This is the first report of the simultaneous resection of disseminated HCC and colon cancer.
\end{abstract}




\begin{tabular}{l|l}
\hline DOI: $\underline{10.1159 / 000346925}$ & $\begin{array}{l}\text { C } 2013 \text { S. Karger AG, Basel } \\
\text { www.karger.com/crg }\end{array}$ \\
\hline
\end{tabular}

Haga et al.: Simultaneous Resection of Disseminated Hepatocellular Carcinoma and Colon Cancer

\section{Introduction}

Hepatocellular carcinoma (HCC) is one of the most common malignancies worldwide [1]. It has been well known that chronic infection with hepatitis B virus (HBV) or hepatitis C virus (HCV), excessive alcohol consumption, and nonalcoholic fatty liver disease serve as major risk factors for HCC development [2]. Since these risk factors result in progression of liver fibrosis, HCC frequently occurs with a background of cirrhotic liver. Exceptionally, HCC sometimes develops in chronic HBV infection in the absence of cirrhosis.

In terms of therapeutic approaches, surgical resection appears to be a reliable therapy for early-stage HCC. Meanwhile, recent therapeutic progress such as local therapies, transarterial chemoembolization and administration of the anti-angiogenic multi-kinase inhibitor sorafenib has enabled the nonsurgical treatment of HCC. Among them, the local ablation therapies including radiofrequency ablation (RFA) and percutaneous ethanol injection therapy (PEIT) are now widely accepted as curative treatments [3]. These therapies are characterized by minimally invasive and repeatable procedures. Recently, it has been reported that RFA achieved a more favorable outcome than PEIT in terms of recurrence and survival $[4,5]$. On the other hand, RFA can have various complications including needle track dissemination of the tumor cells [6]. However, the frequency and clinical course of disseminated HCC located away from the route of needle insertion remains unclear.

Here, we describe a resected case of disseminated HCC in the pelvic cavity, which appeared to be attributable to the local treatment of HCC 6 years prior.

\section{Case Report}

A 75-year-old woman was referred to our hospital because of increased abdominal pain and vomiting. Physical examination revealed tenderness in her lower abdomen, but no muscular defense or rebound tenderness. She had undergone an operation for appendicitis in childhood. Because of chronic liver disease caused by HCV infection, the patient had been followed closely in our hospital for 10 years. She had developed HCCs in the S4 and S5 segments 6 years earlier and received RFA therapy. The diameter of these tumors was 38 and $15 \mathrm{~mm}$, respectively. No intrahepatic recurrence of the HCC was observed for 6 years after treatment. Although serum levels of markers for HCC including $\alpha$-fetoprotein (AFP) and PIVKA-II gradually increased from 2 years prior, she did not show any symptoms. The serum level of AFP was 41.2 and $171 \mathrm{U} / \mathrm{ml}, 2$ years earlier and 1 year earlier, respectively. Likewise, the serum PIVKA-II level was 321.0 and $420 \mathrm{U} / \mathrm{ml}, 2$ years earlier and 1 year earlier, respectively.

On admission, serum levels of hepatobiliary enzymes were normal, and those of blood urea nitrogen $(29 \mathrm{mg} / \mathrm{dl})$ and creatinine $(0.96 \mathrm{mg} / \mathrm{dl})$ were mildly elevated. Complete blood count tests showed a hemoglobin level of $13.3 \mathrm{~g} / \mathrm{l}$ and a white blood cell count of $21,100 / \mu \mathrm{l}$ accompanied by a 'left shift' of neutrophils. Although the patient usually showed thrombocytopenia associated with liver cirrhosis, an increase in her platelet count was observed $\left(27.6 \times 10^{4} / \mu \mathrm{l}\right)$. Serological tests exhibited positivity for anti-HCV antibody and a mild increase in C-reactive protein levels $(2.2 \mathrm{mg} / \mathrm{dl})$. The levels of carcinoembryonic antigen (CEA) and CA19-9 increased to 12.6 and $65.6 \mathrm{U} / \mathrm{ml}$, respectively. In addition, the levels of AFP and PIVKA-II rose to 800.3 and $474 \mathrm{U} / \mathrm{ml}$, respectively.

Colonoscopy revealed a descending colon tumor that encompassed the entire circumference of the lumen. Abdominal contrast-enhanced computed tomography (CT) revealed a descending colon tumor accompanied by minimal perforation and abscess formation 
Haga et al.: Simultaneous Resection of Disseminated Hepatocellular Carcinoma and Colon Cancer

(fig. 1a) and dilatation of the oral side of the intestine (fig. 1b). Of importance, another tumor was detected in the cecum (fig. 1b). Eventually, a left hemicolectomy for the descending colon tumor and partial resection of the cecum for the cecum tumor were performed and both tumors were successfully removed. Simultaneously, a colostomy was also conducted. Macroscopic examination of the resected specimen showed an advanced colon cancer, which was $45 \times 35 \mathrm{~mm}$ in diameter (fig. 2a). Pathological examination revealed that the descending colon tumor was moderately-differentiated tubular adenocarcinoma lacking lymphovascular invasion (fig. 2b). The lesion was determined to be stage IIA (T3N0). Meanwhile, the cecum tumor, which was approximately $40 \mathrm{~mm}$ in diameter, had developed near the scar from the appendectomy (fig. 2c). Unexpectedly, it was diagnosed as poorly-differentiated HCC (fig. 2d). Retrospective re-reading of CT images revealed that a disseminated HCC had emerged in the cecum 2 years earlier and gradually enlarged (fig. 3).

The postoperative course was uneventful. The serum levels of not only CEA and CA19-9 but also AFP and PIVKA-II declined markedly after the operation. Although the artificial anus was closed 3 months after surgery, no recurrence of the colon cancer or disseminated HCC in the pelvic cavity was detected.

\section{Discussion}

In this case, a follow-up CT for surveillance of recurrent HCC had been performed twice a year after the RFA 6 years earlier. Although CT depicted the growth of a cecum tumor from 2 years previously, the tumor was noticed for the first time on admission. These CT findings appeared to be consistent with a gradual elevation in serum AFP and PIVKA-II levels. At that time, little thought was given to the relationship between cecum tumor and HCC dissemination, because the dissemination usually occurs within the first few years after RFA $[7,8]$. There are some reports of high serum levels of both AFP and PIVKA-II in gastric cancer cases $[9,10]$. However, no such findings have been reported for colon cancer. In the end, a definite preoperative diagnosis of the cecum tumor could not be achieved. Considering that an increase in serum AFP and PIVKA-II levels was observed from 2 years previously, not only careful reading of CT scans but also metastatic screening using 18-fluorodeoxyglucose positron emission tomography should be performed for the early diagnosis of disseminated HCC.

Peritoneal dissemination is attributed to direct metastasis from primary tumors in the abdominal cavity. It usually occurs in the terminal stages and is considered inoperable in a wide range of solid tumors including HCC [11]. Local ablation therapies such as RFA have been widely applied to the treatment of HCCs in the early stages. However, RFA can have undesirable complications. In particular, tumor seeding after RFA causes peritoneal dissemination and contributes to a poor prognosis $[7,8]$. Since the tumor seeding usually occurs along the needle track, a disseminated tumor in the pelvic cavity as found in this case is extremely unusual.

Previous reports have shown that subcapsular location for the tumor, poorlydifferentiated pathology, higher serum level of AFP and tumor biopsy prior to RFA all serve as risk factors for tumor seeding $[12,13]$. In this case, we conducted RFA for 2 HCC nodules followed by tumor biopsy. Since the HCC in the S4 segment measured more than $30 \mathrm{~mm}$ in diameter, we conducted transarterial chemoembolization prior to the liver biopsy and RFA. These tumors in S4 and S5 segments were histologically diagnosed as moderately- and well-differentiated HCCs, respectively. The serum level of AFP was only minimally increased 
Haga et al.: Simultaneous Resection of Disseminated Hepatocellular Carcinoma and Colon Cancer

(11.4 U/ml). Therefore, the dissemination of HCC was suspected to be due to the tumor biopsy prior to RFA in this case.

In conclusion, we report a case of disseminated HCC resected with colon cancer concurrently. It would be of importance to closely monitor the recurrence of colon cancer and the peritoneal recurrence of HCC. To our knowledge, the simultaneous resection of disseminated HCC and colon cancer has never been documented previously. After the local treatment of HCC, surveillance for dissemination not only around the liver including the needle track but also in the entire abdominal cavity would be required. Further examinations in large numbers of HCC patients with peritoneal dissemination associated with local treatment appear to be needed to determine a therapeutic strategy and make a prognostic prediction.

\section{Disclosure Statement}

The authors have no conflict of interest.

\section{References}

1 Okuda K: Hepatocellular carcinoma: recent progress. Hepatology 1992;15:948-963.

-2 El-Serag HB: Hepatocellular carcinoma. N Engl J Med 2011;365:1118-1127.

-3 Livraghi T: Radiofrequency ablation, PEIT, and TACE for hepatocellular carcinoma. J Hepatobiliary Pancreat Surg 2003;10:67-76.

-4 Cho YK, Kim JK, Kim MY, Rhim H, Han JK: Systematic review of randomized trials for hepatocellular carcinoma treated with percutaneous ablation therapies. Hepatology 2009;49:453-459.

-5 Orlando A, Leandro G, Olivo M, Andriulli A, Cottone M: Radiofrequency thermal ablation vs. percutaneous ethanol injection for small hepatocellular carcinoma in cirrhosis: meta-analysis of randomized controlled trials. Am J Gastroenterol 2009;104:514-524.

6 6 Tateishi R, Shiina S, Teratani T, Obi S, Sato S, Koike Y, Fujishima T, Yoshida H, Kawabe T, Omata M: Percutaneous radiofrequency ablation for hepatocellular carcinoma. Analysis of 1,000 cases. Cancer 2005;103:1201-1209.

7 Shirai K, Tamai H, Shingaki N, Mori Y, Moribata K, Enomoto S, Deguchi H, Ueda K, Maekita T, Inoue I, Iguchi M, Yanaoka K, Oka M, Ichinose M: Clinical features and risk factors of extrahepatic seeding after percutaneous radiofrequency ablation for hepatocellular carcinoma. Hepatol Res 2011;41:738-745.

-8 Imamura J, Tateishi R, Shiina S, Goto E, Sato T, Ohki T, Masuzaki R, Goto T, Yoshida H, Kanai F, Hamamura K, Obi S, Yoshida H, Omata M: Neoplastic seeding after radiofrequency ablation for hepatocellular carcinoma. Am J Gastroenterol 2008;103:3057-3062.

-9 Kudo M, Takamine Y, Nakamura K, et al: Des-gamma-carboxy prothrombin (PIVKA-II) and alphafetoprotein-producing IIc-type early gastric cancer. Am J Gastroenterol 1992;87:1859-1862.

10 Takahashi Y, Inoue T: Des-gamma carboxy prothrombin (PIVKA-II) and alpha-fetoprotein producing gastric cancer with multiple liver metastases. Pathol Int 2003;53:236-240.

11 Jacquet P, Vidal-Jove J, Zhu B, Sugarbaker P: Peritoneal carcinomatosis from gastrointestinal malignancy: natural history and new prospects for management. Acta Chir Belg 1994;94:191-197.

$\checkmark 12$ Llovet JM, Vilana R, Brú C, Bianchi L, Salmeron JM, Boix L, Ganau S, Sala M, Pagès M, Ayuso C, Solé M, Rodés J, Bruix J; Barcelona Clínic Liver Cancer (BCLC) Group: Increased risk of tumor seeding after percutaneous radiofrequency ablation for single hepatocellular carcinoma. Hepatology 2001;33:1124-1129.

13 Livraghi T, Lazzaroni S, Meloni F, Solbiati L: Risk of tumour seeding after percutaneous radiofrequency ablation for hepatocellular carcinoma. Br J Surg 2005;92:856-858. 


\begin{tabular}{ll|l} 
Case Reports in & \multicolumn{2}{l}{} \\
\cline { 2 - 3 } Gastroenterology & Case Rep Gastroenterol 2013;7:37-43 & $\begin{array}{l}\text { C 2013 S. Karger AG, Basel } \\
\text { www.karger.com/crg }\end{array}$ \\
\cline { 2 - 3 } & DOI: $\frac{10.1159 / 000346925}{}$ & \multicolumn{2}{l}{ Haga et al. Simultaneous Resection of Disseminated Hepatocellular Carcinoma and }
\end{tabular}
Colon Cancer

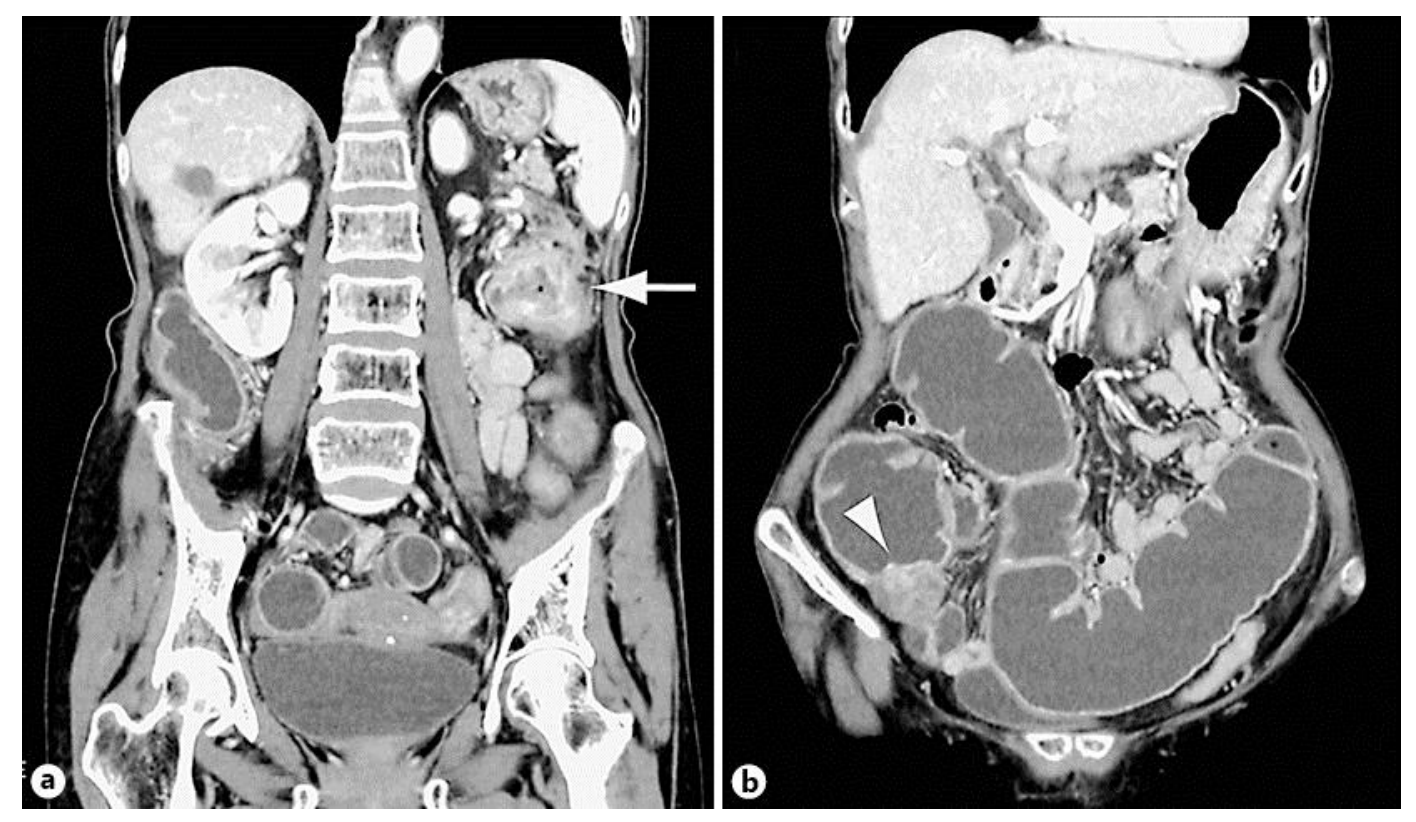

Fig. 1. Findings of contrast-enhanced CT. a CT image of the descending colon cancer (arrow). $\mathbf{b}$ The other tumor adjacent to the cecum (arrowhead) and abnormal dilatation of the ascending and transverse colon are depicted. 


\begin{tabular}{ll|l} 
Case Reports in & \multicolumn{2}{l}{} \\
\cline { 2 - 3 } Gastroenterology & Case Rep Gastroenterol 2013;7:37-43 \\
\cline { 2 - 3 } & DOI: $\frac{10.1159 / 000346925}{}$ & $\begin{array}{l}\text { C 2013 S. Karger AG, Basel } \\
\text { www.karger.com/crg }\end{array}$ \\
\cline { 2 - 3 } & Haga et al: Simultaneous Resection of Disseminated Hepatocellular Carcinoma and
\end{tabular}

Haga et al.: Simultaneous Resection of Disseminated Hepatocellular Carcinoma and Colon Cancer
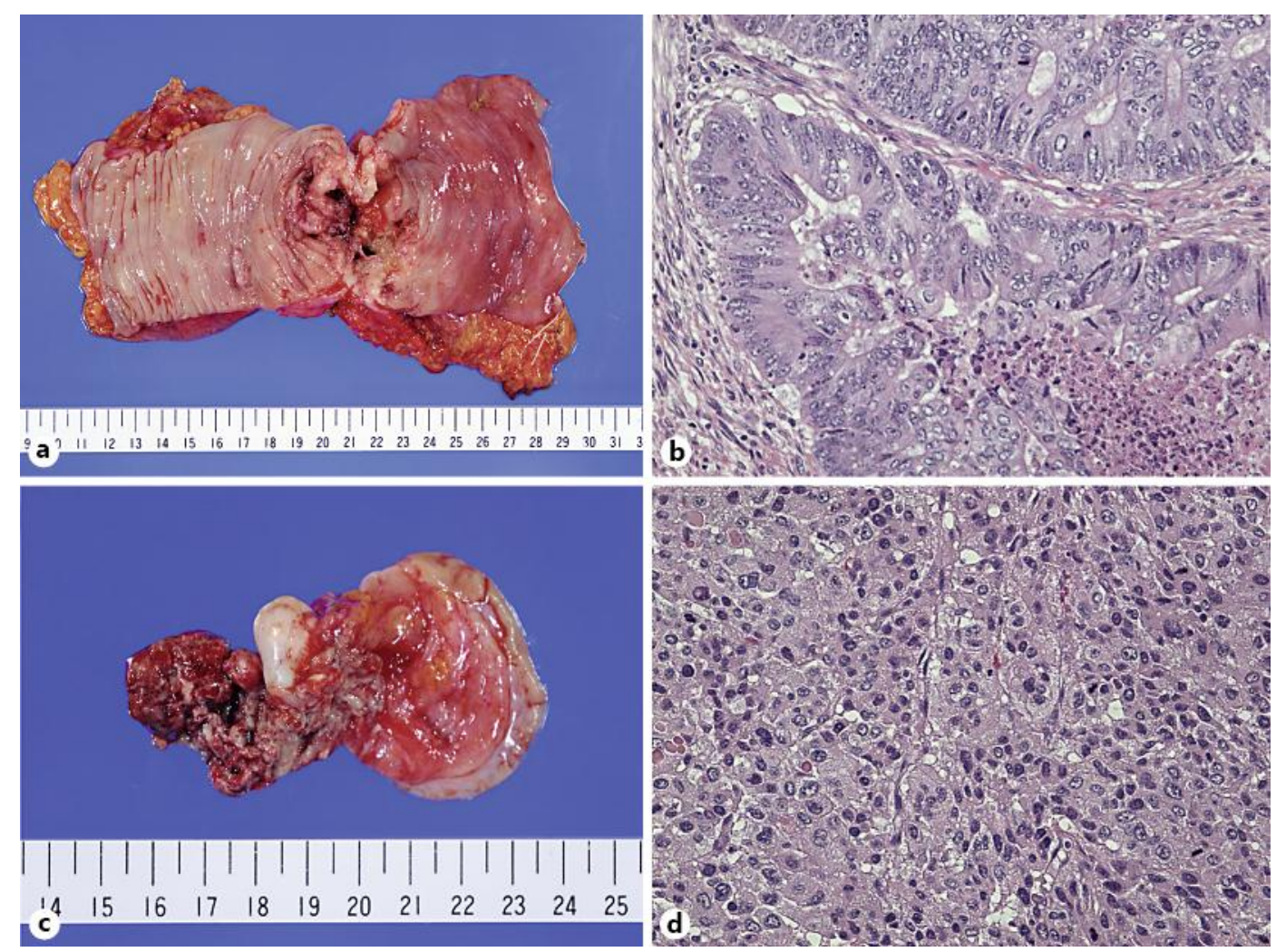

Fig. 2. Pathological examination of the resected specimens of the descending colon tumor and cecum tumor. a, b Macroscopic finding (a) and H\&E staining (b, $\times 200)$ of the descending colon tumor. $\mathbf{c}, \mathbf{d}$ Macroscopic finding $(\mathbf{c})$ and $H \& E$ staining $(d, \times 200)$ of the cecum tumor. 


\begin{tabular}{ll|l} 
Case Reports in & \multicolumn{2}{l}{ Case Rep Gastroenterol 2013;7:37-43 } \\
\cline { 2 - 3 } Gastroenterology & DOI: $\frac{10.1159 / 000346925}{}$ & $\begin{array}{l}\text { C 2013 S. Karger AG, Basel } \\
\text { www.karger.com/crg }\end{array}$ \\
\cline { 2 - 3 } & &
\end{tabular}

Haga et al.: Simultaneous Resection of Disseminated Hepatocellular Carcinoma and Colon Cancer

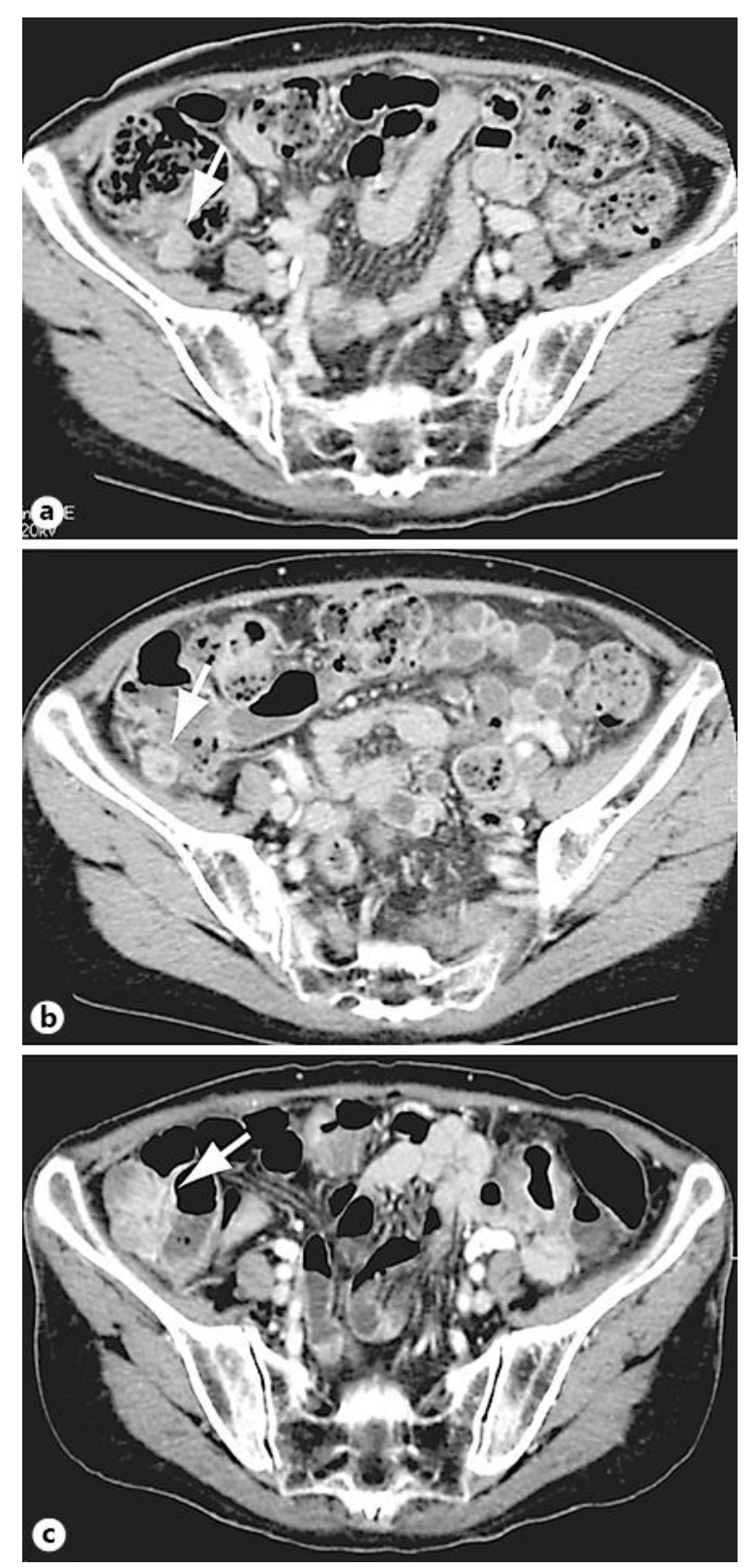

Fig. 3. Time series presentation of CT images. The cecum tumor (arrows) was detected by contrastenhanced CT performed 2 years earlier (a), 1 year earlier (b) and on admission (c). 